\title{
The Final Warming Date of the Antarctic Polar Vortex and Influences on its Interannual Variability
}

\author{
JOANNA D. HAIGH \\ Imperial College London, London, United Kingdom \\ HOWARD K. ROSCOE \\ British Antarctic Survey, Cambridge, United Kingdom
}

(Manuscript received 30 September 2008, in final form 17 June 2009)

\begin{abstract}
More than 40 years of radiosonde data from two Antarctic stations are examined for changes in the date of the final stratospheric warming that occurs each year as the vortex breaks up in spring/summer. A new measure of this date is derived that does not rely on specification of a threshold, as has been common previously. The date of final warming takes between 10 and 40 days to progress from 30 to $100 \mathrm{hPa}$ and occurs 20 30 days later in the 1990s than in the 1960s. Multiple linear regression analyses of these final warming dates, and also of the vertical profile of the southern annular mode (SAM), are presented. Only a weak signal is found for a linear trend, but a significant response is found throughout the atmosphere to ozone mass deficit (OMD), representing stratospheric ozone loss. In the SAM a significant response to the combined influence of solar variability and the quasi-biennial oscillation (QBO) is also found. The seasonal evolution of these signals in the NCEP Reanalysis zonal mean temperatures is examined and their influences on final warming dates is calculated. This confirms that ozone loss is primarily responsible for the delayed warming in the lower stratosphere in recent years, but suggests that the phase of solar activity and the QBO also have an effect. The apparent downward progression of the signal of OMD, and of the combined solar activity and QBO, extends well into the upper troposphere and appears to be caused simply by a delay in the top-down breakup of the vortex.
\end{abstract}

\section{Introduction}

Studies of trends in polar stratospheric temperatures have shown a cooling over recent decades, especially in late spring and early summer, that has been ascribed to both increasing concentrations of carbon dioxide and decreasing concentrations of ozone (Randel and Wu 1999; Thompson and Solomon 2005). These cooling trends appear to propagate downward into the troposphere in summer, and considerable evidence now exists that the state of the polar stratosphere influences the troposphere on time scales of weeks to months. In particular, it appears from analyses of observational data that strong/weak conditions of the Antarctic stratospheric polar vortex are followed by anomalies of simi-

Corresponding author address: Joanna D. Haigh, Blackett Laboratory, Imperial College London, London SW7 2AZ, United Kingdom.

E-mail: j.haigh@imperial.ac.uk lar sign in the circulation of the troposphere (Thompson et al. 2005). One measure of the strength of the vortex is its persistence with deeper, colder vortices tending to last longer into the spring; several studies (including Waugh and Randel 1999; Waugh et al. 1999; Karpetchko et al. 2005; Black and McDaniel 2007) have indicated a trend over the 1980s and 1990s toward a later vortex breakdown.

Two questions arise: First, is it possible to identify specific factors that influence the state of the polar vortex? Second, by what mechanisms do the stratospheric anomalies influence the atmosphere below? In what follows we derive from radiosonde ascents above two Antarctic stations estimates of the date of final warming of the polar vortex based on a measure of the rate of change of temperature at several pressure levels within the lower stratosphere. We present a multiple regression analysis of Southern Hemisphere polar temperatures, using the National Centers for Environmental Prediction (NCEP) reanalysis dataset, designed to show the influence of various 
factors on the seasonal evolution of the polar vortex. We apply the same definition of final warming date as used on the radiosonde temperatures to the NCEP polar data to indicate the extent to which these factors may influence the breakdown of the vortex. Here we do not investigate any specific mechanisms, but analyze the apparent propagation of stratospheric anomalies downward into the troposphere.

\section{Date of final warming of the Antarctic polar vortex}

We use radiosonde data acquired once or twice daily from January 1961 to February 2007 at the South Pole and from April 1957 to February 2007 at Halley $\left(75^{\circ} 35^{\prime}\right.$ S). Measurements are available at pressure levels 100, 50, and $30 \mathrm{hPa}$; data at $70 \mathrm{hPa}$ are also available since January 1962 from Halley and since January 1996 from the South Pole. The records from both stations have occasional gaps of up to several months duration, especially at earlier dates and lower pressures. Examples of the raw measurements from the South Pole throughout two 12-month periods, 1964/65 and 1999/2000, are given in Fig. 1a. A key feature is the steep warming during October or November, occurring later at higher pressures, representing a singlestation perspective on the spring breakdown of the polar vortex.

The definition of the date of vortex breakdown is subjective. Waugh et al. (1999) describe several approaches based on spatial diagnostics such as the area inside a chosen potential vorticity $(\mathrm{PV})$ contour, the meridional gradient of PV at the vortex edge, or the area covered by strong zonal winds. Zhou et al. (2000) use vortex area; Black and McDaniel (2007) choose the zonal mean zonal wind at the core of the jet, defined to be at $\left(60^{\circ} \mathrm{S}, 50 \mathrm{hPa}\right)$. The final warming date is then determined by the time at which one of the diagnostics crosses a predetermined threshold. These measures provide useful objective indications of vortex parameters, including size, shape, and position, and of their evolution through the seasonal cycle. Use of these measures to investigate longer-term (multiannual) variability in the final warming date, however, may be problematic owing to their reliance on a chosen threshold. Waugh and Randel (1999) assess the dependence of the calculated date to the choice of parameter and find that its decadal variability is relatively insensitive to this choice, but this does not allow for long-term variations in the background fields. The same threshold value for the final warming date cannot be assumed to apply to situations in which the vortex is breaking down within different environments, specifically in the context of a general cooling, as the threshold value may be crossed at a different phase of the seasonal cycle.
Here we have used a measure based not on an absolute value of a characteristic of the vortex but on its temporal evolution. This may not provide a better definition, per se, of the final warming date but it does avoid the possibility of the artifacts associated with threshold techniques. This approach could be applied to any of the measures outlined above; here we first demonstrate its use on the radiosonde temperature time series and then apply it to zonal mean high-latitude temperatures from the NCEP reanalysis.

To reduce nonuniformity in sampling, the radiosonde temperatures were first averaged into 3-day periods; they were then smoothed using a base-21 triangular filter. Tests have shown that our results are not sensitive to the choice of these values, provided that the width of the overall filter window is on the order of one month. We have not yet applied our approach to Northern Hemisphere data for which the choice of filter may be more crucial given the much greater variability. However, it is worth noting that our technique coped satisfactorily with the large Antarctic sudden warming of September 2002 , being able to differentiate its shape from that of the final warming.

The impact of the filtering can be seen in Fig. 1b, which shows that while the noisy component of the time series is removed, the main features remain. The seasonal evolution is clear, and its variation with altitude shows the amplitude of the annual cycle increasing with decreasing pressure and phases of the cycle occurring earlier; that is, the spring warming occurring first at higher altitudes and the vortex breakdown occurring progressively later at lower altitudes. As discussed in earlier studies, the definition of final warming date is subjective. One possibility would be to use the time of maximum temperature, but this is somewhat imprecise, especially at higher pressures, due to the flatness of the peaks. Instead, we use the date at which the second derivative, with respect to time, is a minimum. This is much better defined than the maximum temperature, as shown in Fig. 1d, and is also intuitively satisfactory in the sense that it represents the date (at each pressure level) at which the temperatures begin to turn round.

The years presented in Fig. 1 are chosen because they represent examples of an early (1964/65) and late (1999/ 2000) breakdown. The final warming dates at 30, 50, 70, and $100 \mathrm{hPa}$, defined as the date of the minimum in the second derivative, correspond to 7, 17, N/A, and 29 November 1964 and 16, 25, and 31 December and 27 January 1999/2000. Figure 2 shows the values derived, where possible, for each year at each pressure level above the two stations. The mean difference in the corresponding final warming date between pressure levels 30 and 50, 50 and 70 , and 70 and $100 \mathrm{hPa}$ are 12, 7, and 6 days at Halley 
(a)
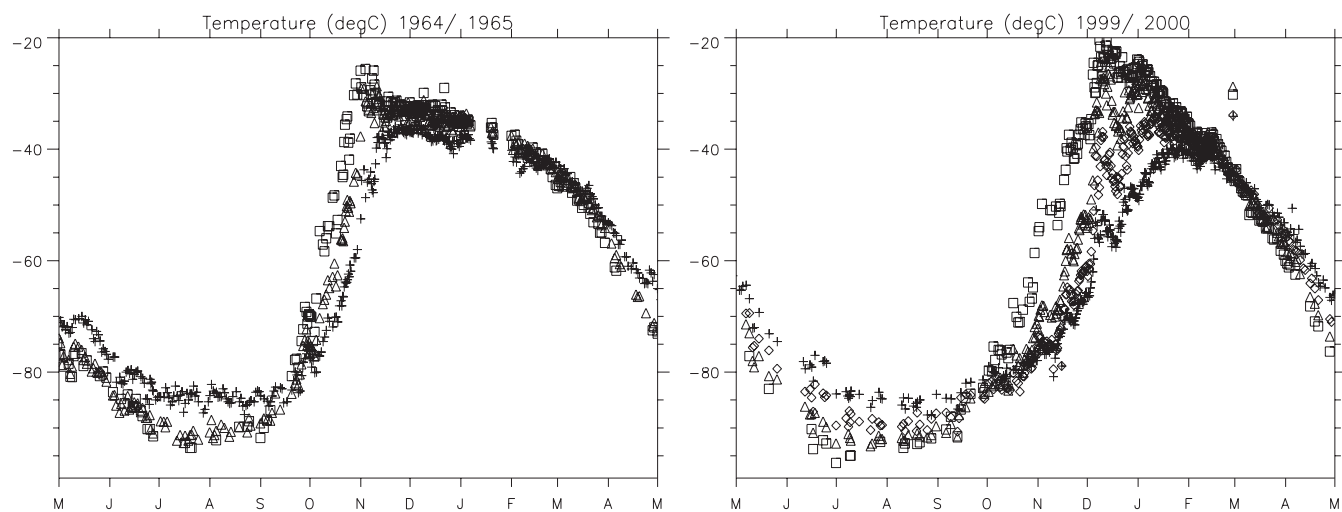

(b)
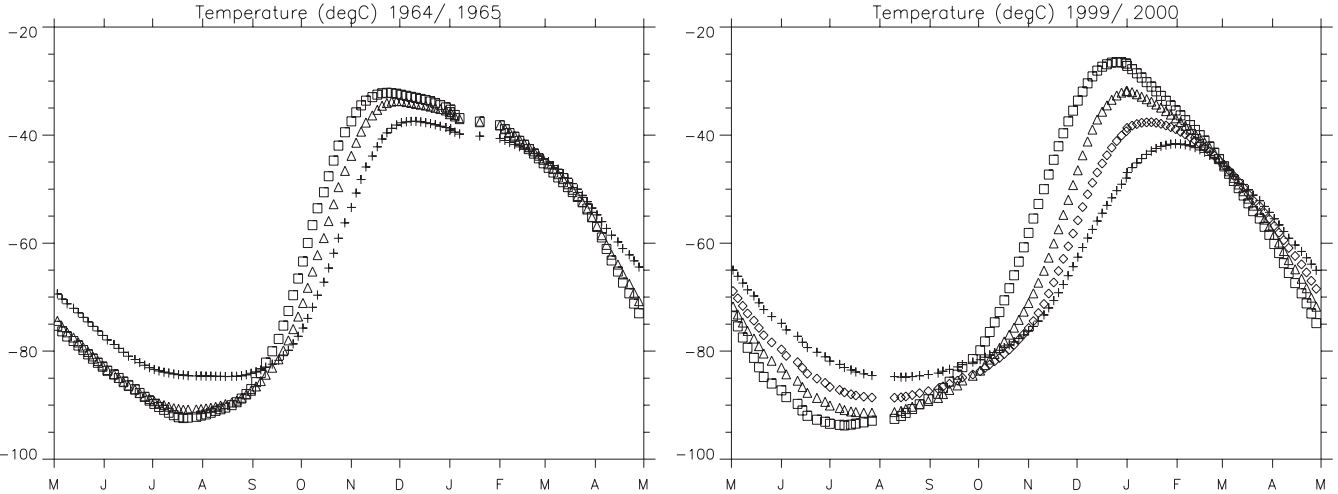

(c)
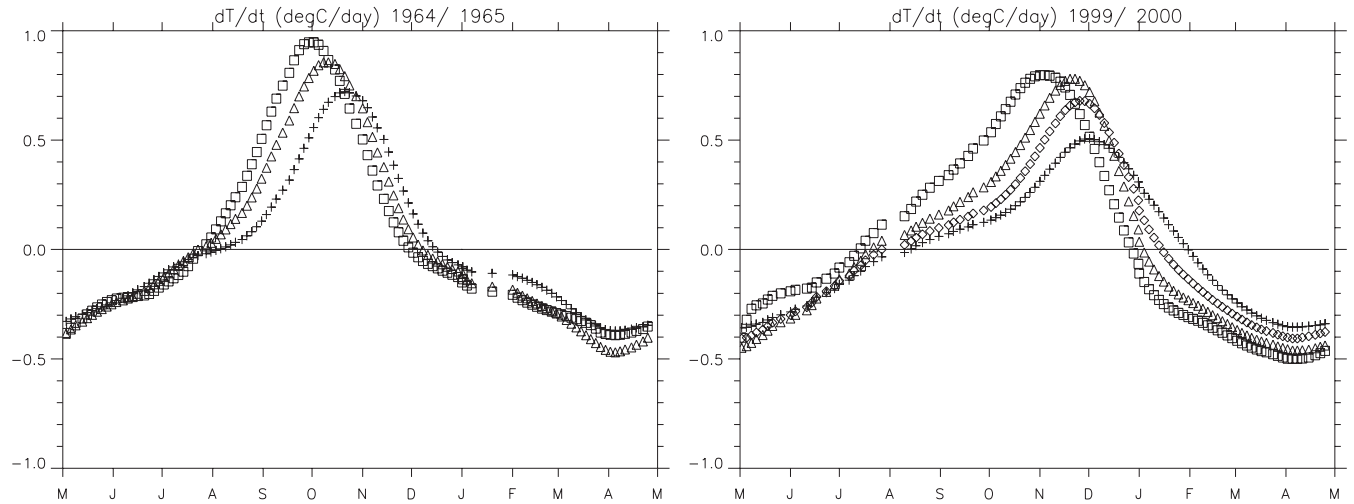

(d)
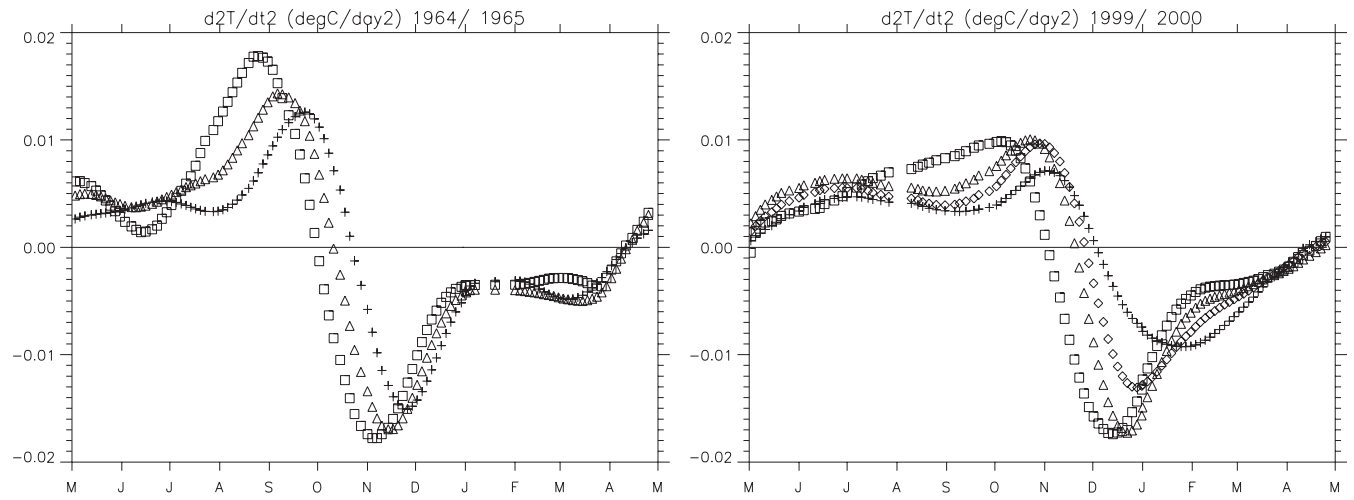

FIG. 1. Temperatures from radiosonde ascents at the South Pole over a year starting 1 May 1964 and 1 May 1999: (a) raw data, (b) data binned into intervals of three days and then smoothed using a base-21 triangular filter, (c) first derivative of (b), and (d) second derivative. Symbols refer to pressure levels at $30 \mathrm{hPa}(\Delta), 50 \mathrm{hPa}(\square), 70 \mathrm{hPa}(\diamond)$ $(1999 / 2000$ only), and $100 \mathrm{hPa}(+)$. The final warming date is defined as the minimum in the second derivative. 
(a)

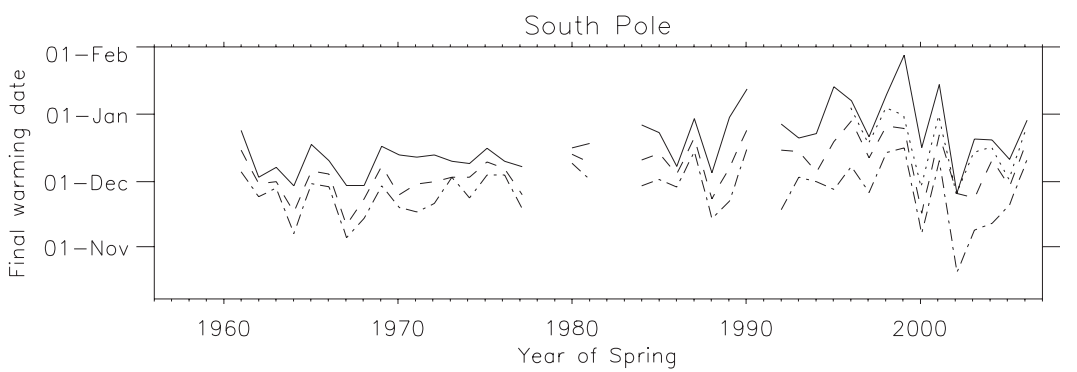

(b)

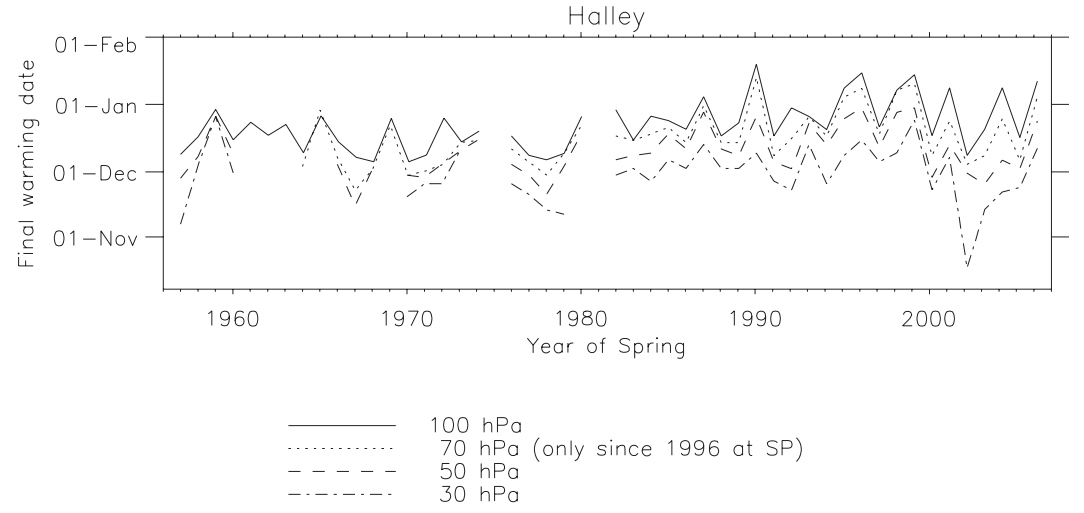

FIG. 2. Date of the final warming each year, defined as the time of the minimum in the second derivative of polar temperature, as in the examples shown in Fig. 1, at the four pressure levels identified in the legend for (a) the South Pole and (b) Halley.

and 11, 8, and 8 days at the South Pole, although these values have large variations. For example, in 2002, when the vortex split in late September, the final warming date appears very early at $30 \mathrm{hPa}$ but is unexceptional at the other levels.

The final warming date is generally earlier in the 1960s and 1970s than in the 1980s and 1990s with a return to somewhat earlier dates since 2000 . As well as the very late breakdown in 1999/2000 both stations show late events in 1990/91, 1995/96, and 2001/02. Although neither station can be taken to represent the behavior of the entire vortex, they show similar characteristics: the correlation coefficients at the four pressure levels between the final warming dates at the two stations are $0.88,0.88,0.91$, and 0.86 . The relative temporal evolutions are also consistent where they overlap, with those representing the entire vortex at $50 \mathrm{hPa}$ of Waugh and Randel (1999; analysis of NCEP data, 1978-97), Black and McDaniel [2007; 40-yr European Centre for Medium-Range Weather Forecasts Re-Analysis (ERA-40), 1978-2001], and Karpetchko et al. (2005; ERA-40, 1958-2001), although none of these studies were in a position to observe the apparent decline since 2000 . The similarity between our radiosonde station results and those from the reanalysis datasets suggests that the earlier dates shown in the radiosonde data during the 1960s and 1970s, and since 2001, may be taken as representative of the vortex as a whole.

\section{Regression analysis}

We now investigate the potential influence of various factors on the temporal evolution of the Antarctic polar vortex using a multiple linear regression technique. Our approach is the same as that used by Haigh (2003), Haigh and Roscoe (2006, henceforth HR06), and Roscoe and Haigh (2007, henceforth RH07). The regression code (M. Allen 2005, personal communication) includes an autoregressive model of noise in the data, representing all sources of observational error, unmodeled variability, internal noise, among others. The variance and autocorrelation of the noise are estimated from the residual between the time series reconstructed from the regression and the data: a red noise function (here assumed to be of order 1) is fitted to the residual, and then the values of regression coefficients and the noise parameters are iterated until the noise model fits within a prespecified threshold. This method minimizes the possibility of noise being interpreted as a signal and also produces, using a Student's $t$ test, measures of the confidence intervals of the resultant coefficients, taking into account any covariance between the indices.

We carry out a number of regressions, each using a range of component indices selected from the following list: 
- a linear trend representing long-term increases in greenhouse gases;

- polar ozone concentration based on ozone mass deficit (OMD) [we use the value below 220 DU, averaged from 19 July to 1 December each year (updated from that of Bodeker et al. 2005) and assumed to be zero before 1979];

- ENSO_the "cold tongue" index from the University of Washington at Seattle (available online at http:// jisao.washington.edu/data_sets/cti/);

- Volcanic aerosol-global average stratospheric aerosol loading (available online at http://data.giss.nasa.gov/ modelforce/strataer/) (we use the tropical mean values);

- Solar activity-the 10.7-cm solar flux from the National Geophysical Data Center (available online at ftp://ftp.ngdc.noaa.gov/STP/SOLAR_DATA);

- The quasi-biennial oscillation-zonal wind at $40 \mathrm{hPa}$ over Singapore (B. Naujokat, Free University of Berlin, 2007, personal communication) [Our results are not sensitive to the pressure level chosen for the QBO winds between 35 and $60 \mathrm{hPa}$ (see the discussion by RH07). We have tried using two quasi-orthogonal time series; however, the introduction of a second index does not substantially improve the fits while it does reduce the number of degrees of freedom, and thus the confidence level.];

- A compound solar-QBO index [HR06 defined a new regression index, composed of the product of the (individually normalized) solar and QBO indices, to be used in place of the separate solar and QBO. It is based on the observation by Labitzke (2004 and previous papers) that Antarctic winter polar stratospheric temperatures vary from being in phase with solar activity when the QBO is westerly (wQBO) to antiphase when the QBO is easterly (eQBO). The formulation of this index is discussed in detail by RH07, and the time series of the compound solar-QBO index, and all the other indices, are presented in Fig. 1 of RH07.]

Each regression index has an independent value for each month of the year. Our choice of indices for the analyses discussed in the next section is determined by the combination that explains the greatest amount of the variance in the data. For example, Fig. 3 presents results of two regressions of time series of the Southern Annular Mode (SAM) index as a function of altitude. The SAM data are the weightings, January 1979-November 2005, of the leading EOF of NCEP reanalysis (Kalnay et al. 1996) monthly-mean geopotential heights, $20^{\circ}-$ $90^{\circ} \mathrm{S}$ at 17 standard pressure levels between 1000 and $10 \mathrm{hPa}$. In constructing the EOFs, only data since 1979 were used owing to the unreliability of reanalyses in these data-poor areas of the Southern Hemisphere in the presatellite era. Figure 3 a shows the results of a re- gression using five indices: linear trend, solar, QBO, stratospheric aerosol, and ENSO. Only the ENSO signal in the troposphere is deemed to be statistical significant at the 5\% level with positive values (El Niño) associated with negative SAM (weaker polar vortex). Enhanced solar activity and stratospheric aerosol are also related (but with low statistical significance) to a weaker vortex. The linear trend shows small positive values in the lower stratosphere and near the surface, indicating a secular strengthening of the vortex. These have been observed by previous authors: Thompson et al. (2000) show a positive linear trend in the SAM at $850 \mathrm{hPa}$ during the period 1968-97 in each month of the year. In the stratosphere the linear trend in the annual mean reflects some compensation between positive values throughout most of the year but negative values in winter, shown in geopotential heights at $50 \mathrm{hPa}$ by Thompson et al. (2000) and through the depth of the stratosphere during the years 1979-2003 by Thompson and Solomon (2005). Inclusion of the later years, 2004/05, in Fig. 3 also tends to reduce the trend due to their relatively low values, as reflected in the final warming dates shown in Fig. 2.

Figure $3 \mathrm{~b}$ shows an analysis of the same SAM data using four regression indices. Two-stratospheric aerosol and ENSO_-are the same as in the upper panel, and their derived signals are essentially unchanged, as would be anticipated for linearly independent indices. The other two are OMD and solar-QBO. The OMD signal is large, positive, and statistically significant at all levels except (marginally) $500 \mathrm{hPa}$; thus, ozone depletion gives a better indicator of long-term variations in the SAM than a linear trend, confirming the findings of RH07 for the SAM in surface pressure gradient, over a longer time. It would be interesting to diagnose the separate contributions of greenhouse gas and ozone depletion to the interannual variability; however, we do not use these two indices simultaneously in a regression as they are too highly correlated. The OMD signal represents the gradual strengthening of the polar vortex from the late 1970 s to the late 1990 s and a subsequent weakening, as well as dynamically induced features such as the small ozone hole of 2002.

The solar-QBO signal is considerably larger than either the solar or QBO components individually; it is negative at all heights, consistent with the Labitzke (2004) findings, and statistically significant at all altitudes below $70 \mathrm{hPa}$. This confirms the findings of HR06 for the SAM at three pressure levels, which showed at 30, 250, and $100 \mathrm{hPa}$ in a similar SAM dataset a strong response to the combined solar*QBO index.

We have also carried out a regression analysis of the time series of the final warming dates calculated in section 2 from the radiosonde data and shown in Fig. 2. No 

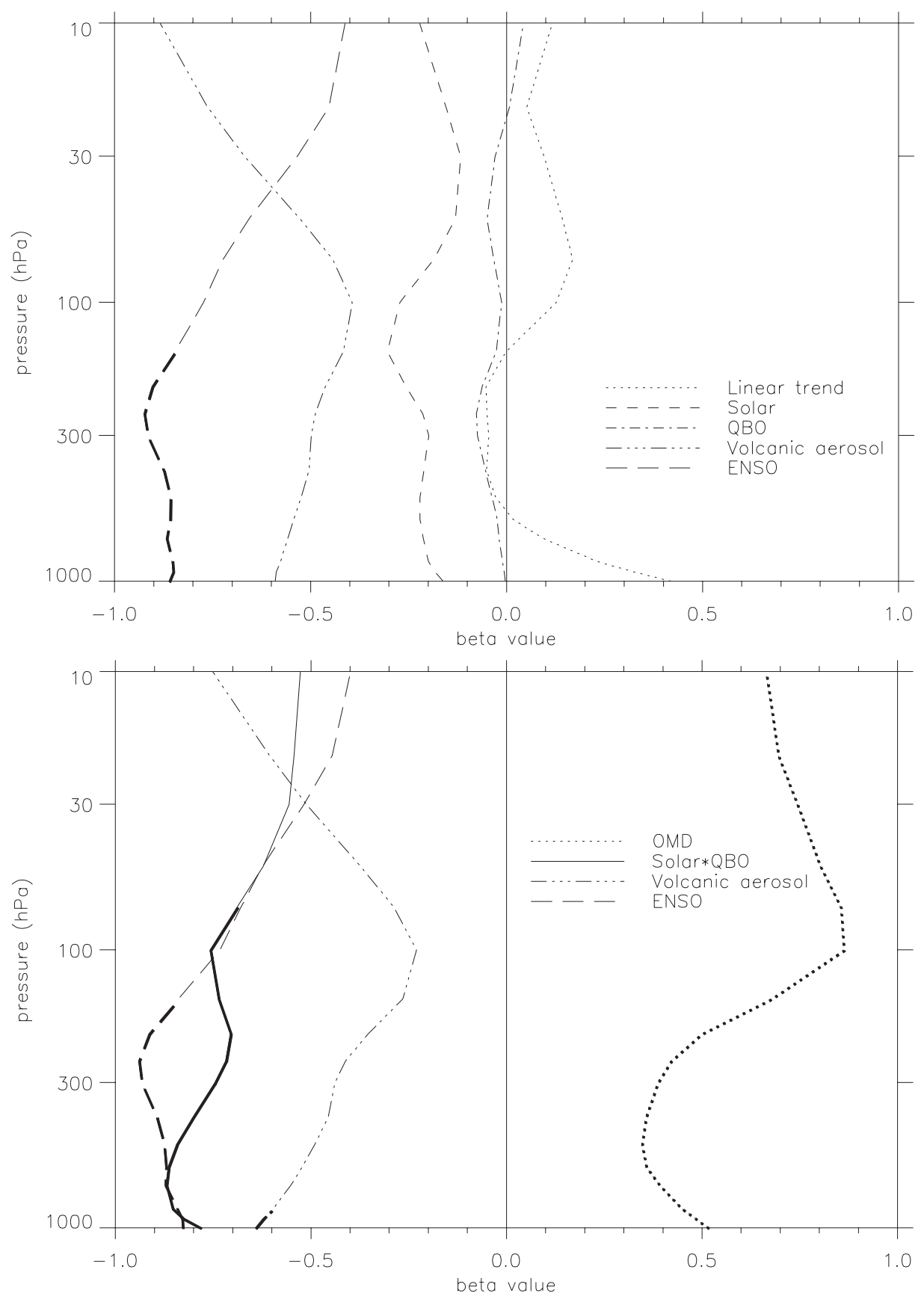

FIG. 3. Results of multiple linear regressions of the SAM index, derived at each standard pressure level from NCEP geopotential height data (see text for details). The indices included in the regressions are identified in the legends within the panels. The beta value is the weight derived for each regression parameter and indicates the difference in the SAM index associated with the maximum and minimum values during the period 1979-2005. Bold sections indicate that the signal is significant at the $5 \%$ level.

significant response is detected to any index apart from those representing long-term trends, and the results for these are summarized in Table 1. A response to OMD, significant at the $5 \%$ level, was found at all levels at
Halley, suggesting that ozone depletion directly influenced the date of final warming. Thus, at the peak of ozone depletion in 1998 vortex breakdown occurred about 20 days later than in preozone hole years. A 
TABLE 1. Results of regression analysis of long-term signals in the time series of the final warming dates from radiosonde data, as shown in Fig. 2. Values give the delay (days) of the final warming date, as defined in the columns. A bold font indicates results where the $t$ value indicates a 5\% confidence interval. No results were obtained for the South Pole at $70 \mathrm{hPa}$ owing to the restricted length of the dataset.

\begin{tabular}{|c|c|c|c|c|c|}
\hline \multirow[b]{2}{*}{ Station } & \multirow[b]{2}{*}{ Pressure $(\mathrm{hPa})$} & \multicolumn{2}{|l|}{ OMD } & \multicolumn{2}{|l|}{ Linear } \\
\hline & & Days (1998 cf pre-1980) & $t$ value & Days (more than 49 years) & $t$ value \\
\hline \multirow[t]{4}{*}{ Halley } & 30 & 17 & 2.3 & 2 & 0.2 \\
\hline & 50 & 18 & 3.0 & 13 & 1.5 \\
\hline & 70 & 21 & 4.4 & 21 & 2.6 \\
\hline & 100 & 20 & 5.9 & 19 & 3.8 \\
\hline \multirow[t]{3}{*}{ South Pole } & 30 & 8 & 1.3 & -1 & 0.2 \\
\hline & 50 & 16 & 3.6 & 17 & 2.4 \\
\hline & 100 & 29 & 7.5 & 32 & 4.5 \\
\hline
\end{tabular}

similar result is found at 50 and $100 \mathrm{hPa}$ at the South Pole, but there is a weaker signal at $30 \mathrm{hPa}$. In all cases the OMD index gives a better fit (higher $t$ value) to the data than a linear trend.

\section{Influences on the seasonal evolution of the Southern Hemisphere polar vortex}

We now investigate how these factors influence the seasonal evolution of the polar vortex by carrying out a multiple regression analysis of monthly-mean NCEP reanalysis (Kalnay et al. 1996) temperatures averaged $60^{\circ}-90^{\circ} \mathrm{S}$ for the period $1979-2005$. First, we demonstrate that the technique used to define the final warming date for the radiosonde data presented in section 2 may be usefully applied to the NCEP temperatures to produce a final warming date profile.

We use monthly mean, rather than daily, NCEP data for our regression analysis because (i) daily values are not available for some of the regression indices (e.g., QBO) and (ii), even if they were, regression of daily data would pick out variability on much shorter time scales than those of the seasonal evolution in which we are interested. We have compared the results of applying the technique used in section 2 on daily NCEP data with those using monthly data and find that the derived fields, and the downward progression of the date of final warming, are very similar to those shown in Fig. 4. This is because the interpolation of the monthly-mean data produces fields that are very similar to the ( $\sim 30$ day) smoothed daily data. In fact, using unsmoothed daily data gives mean dates that differ by less than 0.2 days from those given by the monthly data but with a standard deviation of about six days due to the former being much noisier.

Figure 4a presents the seasonal variation in temperature as a function of pressure, that is, the monthly-mean data averaged over the $27-y r$ period. Figure $4 \mathrm{~b}$ shows the time rate of change of temperature at each pressure level; here the data were interpolated using a cubic spline fit. Figure $4 \mathrm{c}$ shows the second derivative, and the bold line indicates the dates at which this is a minimum at each pressure level; these final warming dates are somewhat later than those found for the radiosonde data at each height because the use of monthly-mean data smoothes out the shoulder present in the higher time resolution measurements. However, as we are interested in relative rather than absolute dates, this is not a concern. As with the radiosonde data, the final warming date occurs later at lower altitudes within the stratosphere, taking 58 days to pass from 30 to $250 \mathrm{hPa}$. The downward propagation, of the minimum in the second derivative, penetrates well into the troposphere, where it may be interpreted as the date of the marked spring weakening in westerly winds rather than of a vortex breakdown. The slack gradients around $400-500 \mathrm{hPa}$, however, make the definition of the date of the minimum more uncertain here.

In our regression analysis of the zonal mean temperatures we use the same four regression indices as in Fig. 3b because extensive testing shows that these almost invariably provide the best fit to the measurements, not only for the SAM index but also the more fundamental geopotential height and temperature records at southern high latitudes. Figure 5 presents some results. The four panels show the signals deduced for OMD, solar* QBO, stratospheric aerosol, and ENSO as a function of time of year and pressure. Shaded areas indicate regions of statistical significance. The OMD signal is negative throughout the year in the stratosphere with the largest cooling, $7.5 \mathrm{~K}$ at $100 \mathrm{hPa}$ in November, at peak levels of the OMD in 1999 relative to the zero ozone depletion of 1979. Our results are somewhat more negative than those derived from Antarctic radiosonde data by Randel and $\mathrm{Wu}$ (1999), which is consistent with their analysis being over a shorter time period, approximately 197590. If we use a linear trend in the regression in place of OMD, our results (not shown) give smaller overall cooling values and small warming trends in the winter stratosphere, similar to the linear trends of Thompson and Solomon (2005). The compensation between warming and cooling signals is responsible for the small trend 
(a)

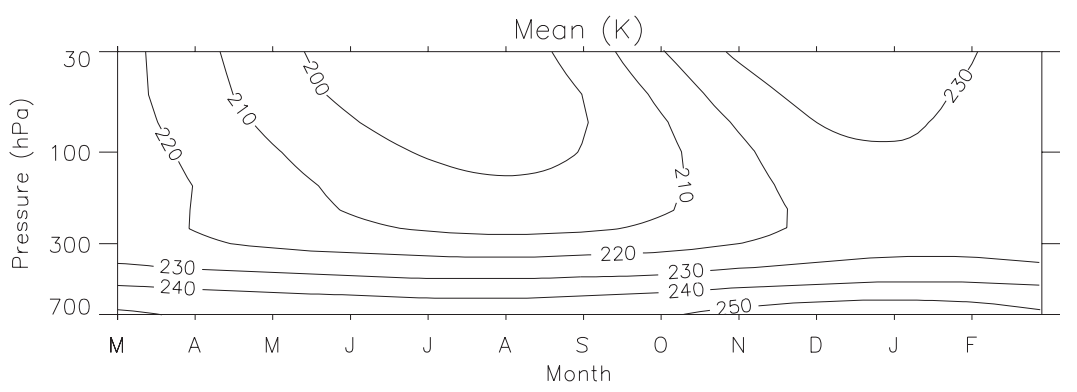

(b)

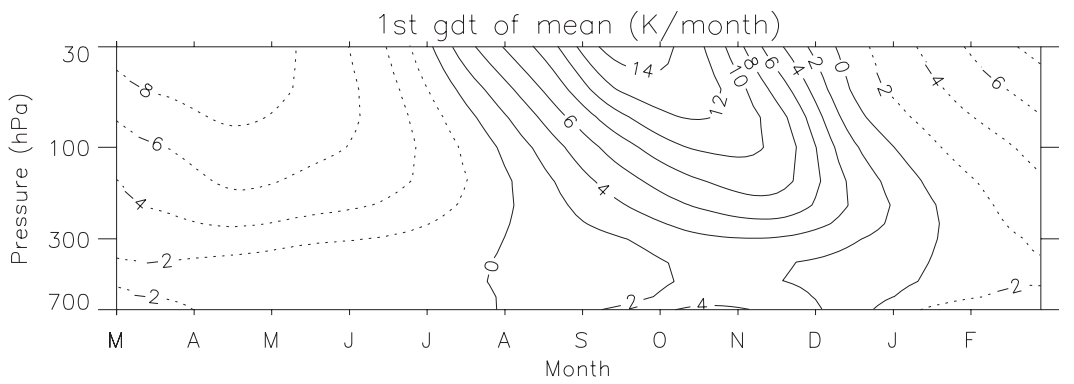

(c)

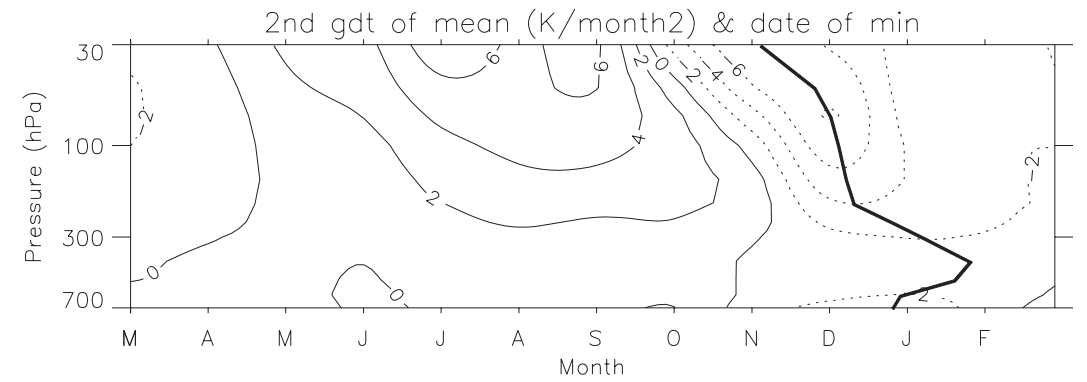

FIG. 4. (a) Zonal-mean monthly-mean temperature averaged between $60^{\circ}$ and $90^{\circ} \mathrm{S}, 1979$ and 2005, from NCEP reanalysis. (b) Rate of change of temperature. (c) Second derivative; the thick line indicates the date of the minimum value of the second derivative. Tick marks on the horizontal axis indicate the middle of the month.

in annual mean SAM shown in Fig. 3. The region of OMD-related cooling appears to take two to three months to propagate downward from the middle stratosphere to the tropopause from where it descends faster to the surface. The positive values seen in the lower troposphere in winter may represent long-term warming, not necessarily attributable to ozone, consistent with the trend observed by Turner et al. (2006) in radiosonde data over the period since 1971 .

Figure 6 shows the seasonal variation in temperature deduced to be appropriate for periods of highest and lowest OMD during the period of the analysis (with all other factors unchanging). Clearly evident is the colder stratosphere throughout the year when ozone is depleted; however, the contours are most different during the final warming period. To investigate this further, we calculate the final warming dates for these two states, as carried out for the mean state in Fig. 4, and the resulting profiles are overlaid in Figs. 5a and 6. Comparison of the two profiles gives an indication of the effect of changing OMD levels on the timing of the final warming: when ozone depletion is at its maximum, the final warming occurs between 12 and 33 days later than when it is minimal, at all altitudes except close to the surface.

The solar-QBO signal is positive at most altitudes throughout most of the year (as evidenced in the annual mean by the weaker polar vortex in Fig. 3); however, a band of negative values is present from $30 \mathrm{hPa}$ in late spring down to the lower troposphere in summer. Thus, during periods of high solar activity and westerly phase $\mathrm{QBO}$, or low sun/eQBO, the stratospheric vortex breaks down later than high sun/eQBO or low sun/wQBO. As in the case of OMD, the delay in final warming date is similar at all altitudes.

Enhanced stratospheric aerosol warms the stratosphere in late spring, due to the extra heating by sunlight scattered back above the aerosol layer, and advances the vortex breakdown at these levels; see Fig. 5c. A similar effect is also seen in the body of the troposphere, but the two are not unambiguously linked. 
(a)

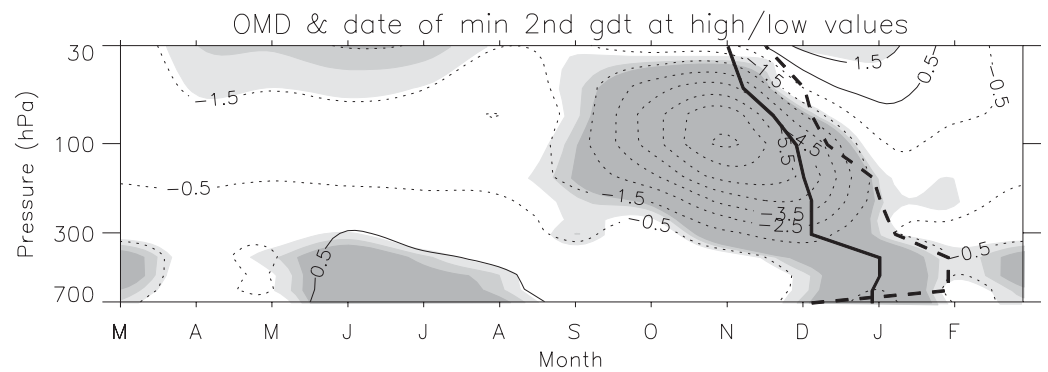

(b)

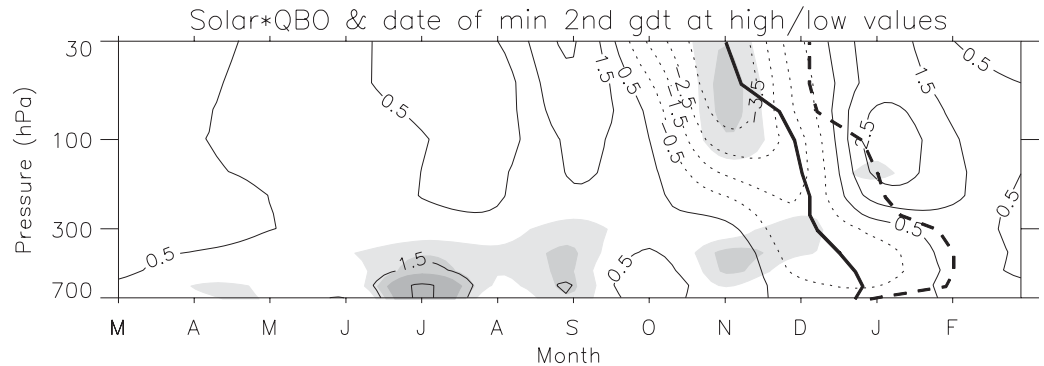

(c)

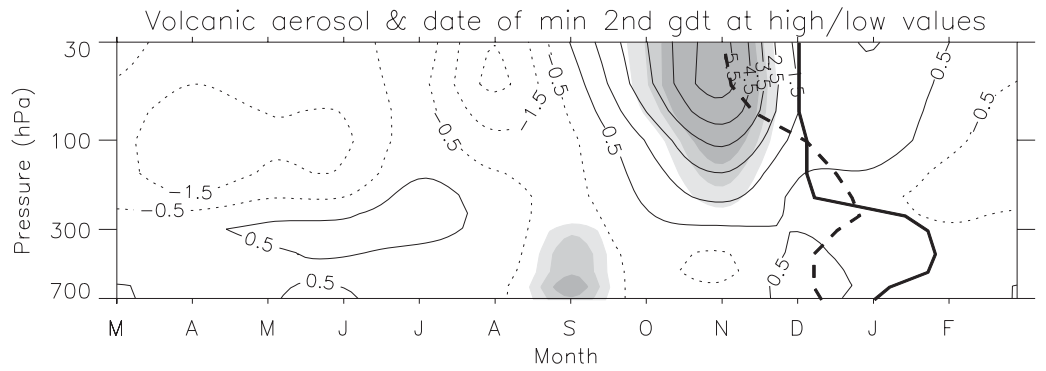

(d)

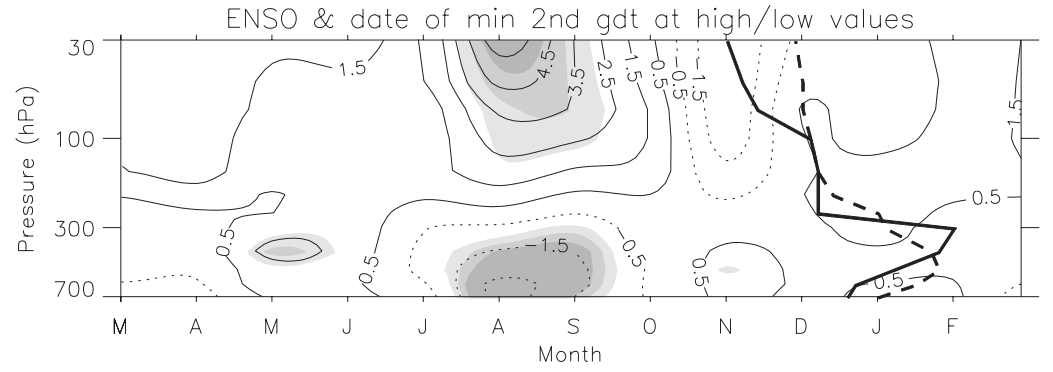

FIG. 5. Results from multiple linear regression analysis of zonal-mean monthly-mean temperature averaged $60^{\circ}-90^{\circ} \mathrm{S}, 1979-2005$, from NCEP reanalysis. Signals deduced for (a) OMD, (b) compound solar-QBO index, (c) stratospheric aerosol, and (d) ENSO. Contour values give the difference between temperatures at dates of highest and lowest values of a given index. Shading indicates regions deduced to be statistically significant at the $5 \%, 10 \%$, and $20 \%$ level. The thick lines indicate the dates of the minimum value of the second derivative at times of high (dashed line) and low (solid line) values of the index. Tick marks on the horizontal axis indicate the middle of the month.

The association of ENSO with the climate of Antarctica has been reviewed by Turner (2004), who notes that nonlinearities in the coupled atmosphere-ocean-sea ice system are likely to confuse attempts to find linear relationships. By way of example, Fogt and Bromwich (2006) suggest a decadal variability in the teleconnection between ENSO and the climate of the high latitude South Pacific. Nevertheless, our linear regression, see Fig. 5d, shows significant high-latitude tropospheric cooling dur- ing July-September related to ENSO warm events along with warming throughout the stratosphere. This is consistent with the GCM simulations of García-Herrera et al. (2006), whose results indicated a strengthened BrewerDobson circulation in the winter hemisphere in response to El Niño events.

These results add to the body of evidence suggesting an influence of the state of the stratosphere on the climate of the troposphere. To further investigate tropospheric 


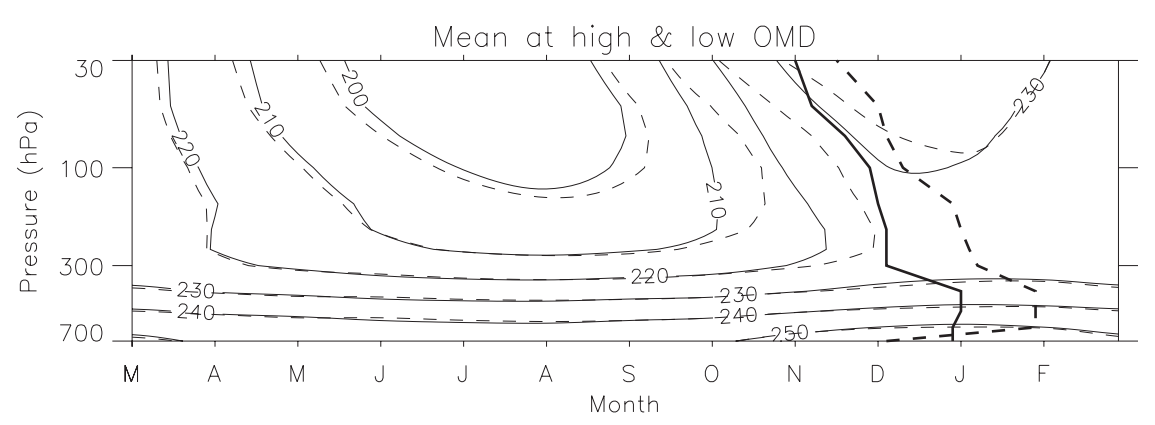

FIG. 6. Temperatures at times of high (dashed lines) and low (solid lines) values of OMD. The thick lines indicate the date of the minimum values of the second derivative at times of high (dashed line) and low (solid line) OMD. Tick marks on the horizontal axis indicate the middle of the month.

behavior, we have studied the zonal mean midlatitude vertical (pressure) velocity $\omega$ at $500 \mathrm{hPa}$. This parameter was chosen as representative of large-scale dynamics: the strength of the Ferrel cell and, by implication, midlatitude eddy activity. The data are again monthly means of NCEP reanalysis data 1979-2005 (inclusive). Figure 7 a shows the climatology of the seasonal evolution of $\omega$ in the $50^{\circ}-70^{\circ} \mathrm{S}$ latitude region; note that negative values imply ascent. The upward branch of the Ferrel cell is strongest and farthest poleward in late winter (AugustSeptember) and weakens and meanders northward during spring. Figure $7 \mathrm{~b}$ presents the signal derived as associated with variations in stratospheric ozone (OMD in a regression analysis). The large negative values during November-March show a strengthening of the ascent, representing a delay in the seasonal migration. This delay, on the order of one month, is consistent with the effect of the OMD on temperatures seen in Fig. 6.

\section{Discussion and conclusions}

The analysis of the radiosonde data presented above confirms, using an improved measure of final warming date, the results of previous studies showing that the date of spring breakdown of the Southern Hemisphere polar vortex moves downward, taking between 10 and 40 days to progress from the middle to lower stratosphere. The multiple regression analysis of these final warming dates

(a)

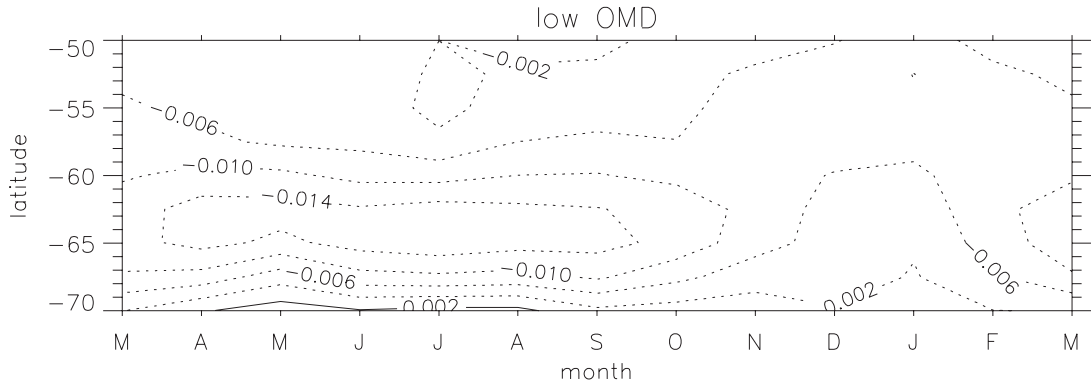

(b)

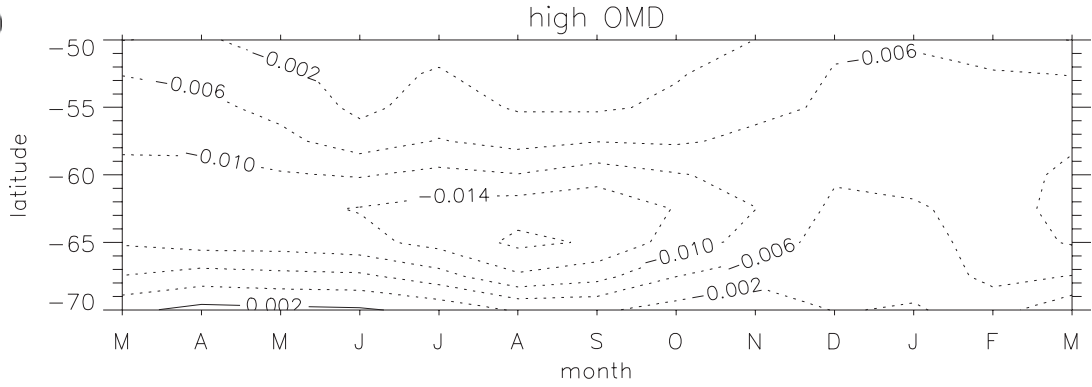

FIG. 7. Seasonal evolution of zonal-mean monthly-mean pressure velocity $\left(\mathrm{Pa} \mathrm{s}^{-1}\right)$ at $500 \mathrm{hPa}, 1979-2005$, from NCEP reanalysis: fields at times of (a) low and (b) high OMD from multiple regression analysis. 
shows that interdecadal variability can largely be ascribed to changes in stratospheric ozone concentration. The analysis of the NCEP zonal-mean polar temperatures confirms these results and shows that the delay in seasonal evolution progresses well into the troposphere. It also shows that variations in the phase of the QBO, modulated by the solar activity cycle, may be responsible for similar delays/advances in the date of vortex breakdown through the stratosphere and upper troposphere.

These results also suggest that rather than introducing some disturbance that propagates downward through the stratosphere, ozone depletion (and the combined effects of solar variability and the QBO) influences polar temperatures by delaying the breakdown of the polar vortex. The mechanism involved thus relates to influences on the initiation of the normal top-down breakup; the sensitivity to ozone is likely related to radiative heating in the mesosphere. Details of the solar-QBO effect are less certain but probably relate to adiabatic warming in response to changes in the Brewer-Dobson circulation induced by variations in planetary wave transmission. Similar arguments would apply to other factors affecting the thermal balance of the polar stratosphere, including greenhouse gas concentrations. Thus, an understanding of the mechanisms whereby the stratosphere exerts an influence on tropospheric climate, at least at high latitudes, might benefit from more detailed investigation of the processes involved in the natural seasonal evolution of polar temperatures.

Acknowledgments. We are grateful to Steve Colwell (British Antarctic Survey) for access to the radiosonde data and to Myles Allen (Oxford University) for providing the regression code. The British Antarctic Survey is funded by the U.K. Natural Environment Research Council.

\section{REFERENCES}

Black, R. X., and B. A. McDaniel, 2007: Interannual variability in the Southern Hemisphere circulation organized by stratospheric final warming events. J. Atmos. Sci., 64, 2968-2974.

Bodeker, G. E., H. Shiona, and H. Eskes, 2005: Indicators of Antarctic ozone depletion. Atmos. Chem. Phys., 5, 2603-2615.
Fogt, R. L., and D. H. Bromwich, 2006: Decadal variability of the ENSO teleconnection to the high-latitude South Pacific governed by coupling with the Southern Annular Mode. J. Climate, 19, 979-997.

García-Herrera, R., N. Calvo, R. R. Garcia, and M. A. Giorgetta, 2006: Propagation of ENSO temperature signals into the middle atmosphere: A comparison of two general circulation models and ERA-40 reanalysis data. J. Geophys. Res., 111, D06101, doi:10.1029/2005JD006061.

Haigh, J. D., 2003: The effects of solar variability on the Earth's climate. Philos. Trans. Roy. Soc. London, A361, 95-111.

— , and H. K. Roscoe, 2006: Solar influences on polar modes of variability. Meteor. Z., 15, 371-378.

Kalnay, E., and Coauthors, 1996: The NCEP/NCAR 40-Year Reanalysis Project. Bull. Amer. Meteor. Soc., 77, 437-471.

Karpetchko, A., E. Kyrö, and B. M. Knudsen, 2005: Arctic and Antarctic polar vortices 1957-2002 as seen from the ERA-40 reanalyses. J. Geophys. Res., 110, D21109, doi:10.1029/ 2005JD006113.

Labitzke, K., 2004: On the signal of the 11-year sunpot cycle in the stratosphere over the Antarctic and its modulation by the quasi-biennial oscillation (QBO). Meteor. Z., 13, 263-270.

Randel, W. J., and F. Wu, 1999: Cooling of the Arctic and Antarctic polar stratospheres due to ozone depletion. J. Climate, 12, $1467-1479$

Roscoe, H. K., and J. D. Haigh, 2007: Influences of ozone depletion, the solar cycle and the QBO on the Southern Annular Mode. Quart. J. Roy. Meteor. Soc., 133, 1855-1864.

Thompson, D. W. J., and S. Solomon, 2005: Recent stratospheric climate trends as evidenced in radiosonde data: Global structure and tropospheric linkages. J. Climate, 18, 4785-4795.

, J. M. Wallace, and G. C. Hegerl, 2000: Annular modes in the extratropical circulation. Part II: Trends. J. Climate, 13, 1018-1036.

_- M. P. Baldwin, and S. Solomon, 2005: Stratosphere-troposphere coupling in the Southern Hemisphere. J. Atmos. Sci., 62, 708-715.

Turner, J., 2004: The El Niño-Southern Oscillation and Antarctica. Int. J. Climatol., 24, 1-31.

T. A. Lachlan-Cope, S. Colwell, G. J. Marshall, and W. M. Connolley, 2006: Significant warming of the Antarctic winter troposphere. Science, 311, 1914-1917.

Waugh, D. W., and W. J. Randel, 1999: Climatology of Arctic and Antarctic polar vortices using elliptical diagnostics. J. Atmos. Sci., 56, 1594-1613.

— — - S. Pawson, P. A. Newman, and E. R. Nash, 1999: Persistence of the lower stratospheric polar vortices. J. Geophys. Res., 104, 27 191-27 201.

Zhou, S. T., M. E. Gelman, A. J. Miller, and J. P. McCormack, 2000: An inter-hemisphere comparison of the persistent stratospheric polar vortex. Geophys. Res. Lett., 27, 1123-1126. 